\title{
A corps et à tri
}

Le corps humain est une machine complexe qui doit chaque jour nous émerveiller, moins par sa bienfacture que par les questions renouvelées qu'il suscite et auxquelles toutes les réponses ne sont pas données.

Ce n'est pas simplement une «complication», c'est aussi une réflexion incessante, une âme, un esprit, avec leurs contingences et leurs aspects imprévisibles.

Le corps peut être blessé, rongé, amputé ... Il peut souffrir et parfois bien se reconstruire. Il a de surcroît une mémoire et les souffrances qu'il endure, comme le bien-être qu'il ressent, restent inscrits et ressortent à l'une ou l'autre occasion.

Il en va de même pour le corps médical. Certes, il est une construction plus difficile à cerner et ses membres n'obéissent pas à la même logique. Mais son esprit et sa mémoire en font un tout cohérent. Par ces temps agités, il souffre et prend des coups. Les blessures sont parfois profondes, béantes, mais la cicatrisation viendra.

Et la mémoire enregistre et retient.

Elle retiendra notamment les plaies successives que le monde politique lui inflige depuis quelques années. Il encaisse, la plaie se cicatrise et les tissus se reconstruisent. Mais la cicatrice demeure, comme les adhérences, jusqu'à ce que vienne la saturation, brutale et révoltée.

Les dernières plaies ont pour nom la clause $\mathrm{du}$ besoin, l'ambulatoire et, qui sait, la menace de la fin de l'obligation de contracter.

La clause du besoin - qui n'a rappelons-le ici - atteint aucun de ses objectifs, a surtout fait naître et se développer chez nos jeunes confrères la notion du syndicalisme actif, de la négociation, mais aussi de la «manif» et de la grève. Même les Vaudois s'y sont mis - et avec succès eux pourtant réputés calmes et ronds, voire patelins.

La fin de l'obligation de contracter sera peutêtre le déclic, la goutte de trop, qui déclencheront chez leurs aînés ce même réflexe.

Il est touchant de lire M. Frick, Président de la Commission Sécurité Sociale et Santé du Conseil des Etats, qui prétend instaurer la fin de l'obligation de contracter pour rassurer la population quant aux capacités du monde politique à opposer à l'initiative socialiste un contre-projet valable. Leurre et illusion! Le peuple n'est pas dupe. Il veut conserver son système de santé actuel - dont il paie chaque année le prix depuis que les pouvoirs publics ne l'assument plus autant qu'avant - et il saura le dire le moment venu.

Caisse unique, prime proportionnelle au revenu? Et pourquoi pas après tout? Plutôt avoir un interlocuteur unique et responsable au lieu d'assureurs déjà omniprésents et obnubilés par le commerce et la concurrence.

La globalisation, la concurrence sauvage et le libéralisme au plus mauvais sens du terme n'ont pas leur place dans l'assurance sociale. Cette conviction s'installe et c'est bien ce message que le corps médical est prêt à faire passer le moment venu, lorsqu'il aura été trop blessé et qu'il sera confronté au tri des seuls assureurs.

Jean Guinchard, Secrétaire général de l'Association des Médecins du canton de Genève 